\title{
The Prevalence of Coagulopathy and Associated Factors Among Adult Type II Diabetes Mellitus Patients Attending the University of Gondar Comprehensive Specialized Hospital, Northwest Ethiopia
}

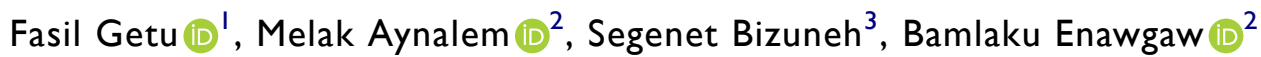 \\ 'Department of Medical Laboratory Sciences, College of Medicine and Health Sciences, Jigjiga University, Jigjiga, Ethiopia; ${ }^{2}$ Department of Hematology \\ and Immunohematology, School of Biomedical and Laboratory Sciences, College of Medicine and Health Sciences, University of Gondar, Gondar, \\ Ethiopia; ${ }^{3}$ Department of Internal Medicine, School of Medicine, College of Medicine and Health Sciences, University of Gondar, Gondar, Ethiopia \\ Correspondence: Fasil Getu, Department of Medical Laboratory Sciences, College of Medicine and Health Sciences, Jigjiga University, PO Box 1020 , \\ Jigjiga, Ethiopia, Tel +25I 927436332, Email fasilgetu85@gmail.com
}

Introduction: Diabetes mellitus is a heterogeneous disorder of metabolism which results hyperglycemic-related atherothrombotic complications. These complications are the leading cause of death in diabetes mellitus patients. Therefore, this study was aimed to determine the prevalence of coagulopathy and associated factors among adult type II diabetes mellitus patients attending at University of Gondar comprehensive specialized hospital.

Methods: A facility-based cross-sectional study was conducted among 357 study participants. A questionnaire and a data collection sheet were used to collect the sociodemographic and clinical data, respectively. About $6 \mathrm{~mL}$ of venous blood samples were collected for coagulation tests and complete blood count. For prolonged coagulation tests, a mixing test was performed. Data were entered into EpiInfo and exported to SPSS for statistical analysis. Then, descriptive statistics were done. A binary and multivariable logistic regression model was used to identify the associated factors. P-value $<0.05$ was considered as statistically significant.

Results: In this study, 357 study participants were included. Of them, 52.1\% (186) and 80.7\% (288) were females and urban residences, respectively. The prevalence of coagulopathy was $26.6 \%$ (95\% CI: $22.1,31.5 \%)$. Out of this, $12.3 \%$ and $8.7 \%$ showed shortened PT and aPTT, respectively. In addition, the prevalence of prolonged PT and aPTT were 5.6\% and 3.9\%, respectively. From the prolonged PT and aPTT, the prevalence of factor deficiency was 95\% and 92.8\%, respectively. Being female (AOR = 2.06; 95\% CI: $1.11-3.85 \%)$, abnormal BMI (AOR $=1.94 ; 95 \%$ CI: $1.08-3.50)$, and educational status of high school $(\mathrm{AOR}=0.26 ; 95 \% \mathrm{CI}$ : $0.10-0.83 \%$ ) were significantly associated with hypercoagulation.

Conclusion: Coagulopathy is an important public health problem among type II diabetes mellitus patients. Being female and having abnormal BMI were associated with hypercoagulation. Therefore, regular monitoring of coagulation parameters is vital to reduce the consequence of coagulopathy.

Keywords: coagulopathy, mixing study, type II diabetes mellitus, Gondar, Ethiopia

\section{Background}

Diabetes Mellitus (DM) is a group of diseases that is described by hyperglycemia state which arises due to failure of insulin production, action, or both. ${ }^{1}$ Diabetes mellitus is etiologically categorized into two types: type I and type II. ${ }^{2}$ Type I DM accounts for $5-10 \%$ of all diabetes cases and is characterized by the destruction of insulin-producing $\beta$-cell of the islets of the pancreas by an autoimmune reaction. ${ }^{3}$ There is a complete insufficiency of insulin in type I DM. Type I DM 
is usually seen in children but it can also arise at any age. ${ }^{4}$ Type II DM (T2DM) is the major type of diabetes, corresponding to $90-95 \%$ of all cases of diabetes worldwide. ${ }^{5}$

The chronic hyperglycemia state in DM affects various stages of coagulation such as clot formation, platelet activation, endothelial cell function, and fibrinolysis. ${ }^{6}$ Type II DM is related to a quantitative increase in platelet surface proteins such as Glycoprotein Ib (GPIb) and GPIIbIIIa molecules. ${ }^{7}$ All changes result in the initiation of thrombus formation. ${ }^{8}$ Abnormally prolonged activated Partial Thromboplastin Time (aPTT) and/or Prothrombin Time (PT) tests may result from the clotting factor deficiency or presence of pathological factor inhibitors. ${ }^{9}$ Pathological coagulation factor inhibitors are usually antibodies that attach and neutralize pro-coagulant molecules. ${ }^{10}$ These pathological inhibitors can be specific or non-specific. ${ }^{11}$

Eighty percent of T2DM deaths are caused by thrombotic death, of which $75 \%$ are caused by cardiovascular incidents. ${ }^{12}$ Atherothrombotic complications are the leading cause of death in DM patients. Studies revealed that being female, old age, duration of T2DM, obesity, and poor glycemic control were also associated with the development of hypercoagulation. ${ }^{13,14}$ Hence, the PT test is used to screening and assesses disorders involving factors from the extrinsic and common coagulation pathway (Factor I, II, V, VII, and X). ${ }^{15}$ Whereas, aPTT is used to screen coagulation factors from the intrinsic and common coagulation pathways like factors I, II, V, VIII, IX, XI, and XII. ${ }^{16}$ Further, the mixing test is also an important indicator of the presence of clotting factor deficiency or the presence of pathological coagulation inhibitors. ${ }^{17}$ It is performed by mixing equal amount of patient plasma with Normal Pooled Plasma (NPP) and correction of coagulation time was measured. ${ }^{18}$

Diabetes mellitus is a main public health concern across the world that affects millions of people each year. ${ }^{19}$ Conforming to the 2019 International Diabetic Federation (IDF) report globally, an estimated 463 million adults are living with DM in the age group of 20-79 years. The IDF also reported that in 2019 about 4.2 million people died in the age group of 20-79 years. ${ }^{20,21}$ In Africa, the prevalence is approximately 19.4 million adults aged 20-79 years. Death due to diabetes in Africa region is reported to be $366,200{ }^{20,21}$ In Ethiopia, it is estimated that 1,699,400 adults or 3.2\% of the adult population are living with diabetes. ${ }^{22}$ A study conducted in Ethiopia showed that, about $58.8 \%$ of T2DM individuals have a hemostatic abnormality. ${ }^{23}$ A related study also found that in untreated cases of DM, aPTT is shortened relative to treated DM patients and non-diabetic patients. ${ }^{24}$

Even though there were limited studies conducted on the coagulopathies among T2DM patients, most of the studies were comparative cross-sectional with small sample sizes. Moreover, the results have been inconsistent and factors associated with coagulopathies were not studied well. Therefore, this study aims to determine the prevalence of coagulopathy and associated risk factors among T2DM patients. This study also tried to differentiate the presence of clotting factor deficiency or pathological factor inhibitors through a mixing test.

\section{Materials and Methods}

\section{Study Setting and Study Population}

A hospital-based cross-sectional study was used to determine the prevalence of coagulopathy and associated factors among adult T2DM patients. This study was conducted at the University of Gondar Comprehensive Specialized Hospital (UoGCSH) from March to June 2021. The hospital is found in Gondar town which is $737 \mathrm{~km}$ away from Addis Ababa, the capital city of Ethiopia. According to the 2007 Ethiopian census report, Gondar town has a total population of 207,044, and more than half $(108,924)$ of them are females. ${ }^{25}$ The population of Gondar town in 2021 is estimated to be $378,000{ }^{26}$ The hospital is providing different medical services to more than 7 million people in the region and people of the neighboring region.

\section{Inclusion Criteria}

A total of 357 study participants were included. All adult T2DM patients that attend the chronic illness clinic of the UoGCSH and willing to participate in this study were included. 


\section{Exclusion Criteria}

Study participants taking antithrombotic agents like warfarin, heparin, and aspirin within 10 days before sample collection, patients who had undergone a recent surgical procedure, history of venous thromboembolism, patients with known inherited coagulation disorders, cancer, hyperthyroidism, and severely ill patients were excluded from the study.

\section{Operational Definitions}

Coagulopathy: A prolonged or shorted PT and/or aPTT values out of the accepted reference range or abnormality in platelet count number. ${ }^{27}$

Hypercoagulation: Shortening of PT and/or aPTT results and an increase in platelet count. ${ }^{12}$

Normal platelet count: The normal platelet count in adults is between 150,000 and $450,000 / \mu \mathrm{L}^{28}$

Normal time for PT: The normal time for PT in adults is between 10 and 16 seconds $^{29}$

Normal time for aPTT: The normal time for aPTT in adults is $24-36$ seconds $^{29}$

Anemia: Anemia in an adult is defined as a hemoglobin level of $<12 \mathrm{~g} / \mathrm{dL}$ for Females and $<13 \mathrm{~g} / \mathrm{dL}$ for Males. ${ }^{30}$

\section{Data Collection Procedure}

\section{Sociodemographic Characteristics and Behavioral Data Collection}

A semi-structured and pretested questionnaire was used to collect sociodemographic and behavioral data from eligible diabetic patients. The questionnaire was used to make face to face interviews with the participants. The sociodemographic data that were included were age, sex, occupation, residence, and level of education. Behavioral data such as the habit of regular physical exercise and cigarette smoking were collected using questionnaire with a face-to-face interview by trained nurses working in the chronic illness clinic of the UoGCSH.

\section{Clinical Data Collection}

Clinical data including duration of DM, duration of antidiabetic drug intake, blood Pressure, and other related data were collected by trained nurses from the patient's medical chart using data collection sheets. The weight and height of the study participants were measured and were used for the calculation of Body Mass Index (BMI).

Body Mass Index: The BMI is calculated after careful measurement of the weight and height of the study participants. The formula used for calculating BMI is weight in $\mathrm{kg}$ divided by height in meter square.

\section{Blood Sample Collection}

About 6 milliliters of venous blood samples were collected using the vacutainer method. About $3 \mathrm{~mL}$ of blood was collected to a tube containing tri-potassium Ethylene Diamine Tetra acetic Acid (EDTA) and $2.7 \mathrm{~mL}$ of blood was collected to a tube that contains $0.3 \mathrm{~mL}$ of $3.2 \%$ sodium citrate. The EDTA anticoagulated blood was used for Complete Blood Count (CBC) tests and peripheral blood film. The sodium citrate anticoagulated blood was used for PT, aPTT, and mixing tests.

\section{Laboratory Processing}

Platelet poor plasma preparation: A Platelet Poor Plasma (PPP) was prepared from all study participants. The PPP was prepared from the sodium citrate anticoagulated blood sample. The sodium citrate anticoagulated whole blood sample was centrifuged at $1500 \mathrm{~g}$ for 15 minutes. $^{31}$

Platelet count: The Beckman Coulter UniCel DxH 800 fully automated hematology analyzer was used to determine the $\mathrm{CBC}$ result. The coulter principle is used in the $\mathrm{DxH} 800 \mathrm{CBC}$ analyzer. A small opening (aperture) between electrodes is the sensing zone through which suspended particles pass. Coulter measures the displaced volume as a voltage pulse, the height of each pulse being proportional to the volume of the cell and frequency of electrical pulse being proportional to cell count. The system counts the individual cells and provides cell size distribution. The COULTER VCS (Volume, Conductivity, and Scatter) established WBC differential technology using three measurements: individual cell volume, high-frequency conductivity, and laser-light scatter. 
PT and aPTT test: - The coagulation profile test was carried out by using a HUMACLOT DUE PLUS coagulation analyzer which uses the turbidity meter principle. The principle of PT is coagulation system stimulation in a plasma in the presence of tissue factors (Apo protein and Phospholipid) and $\mathrm{CaCl}_{2}$. This leads to stable clot development. The time from activation to the formation of a stable clot is recorded in seconds. ${ }^{32}$ The principle of aPTT test is coagulation system activation in a plasma sample in the presence of a platelet substitute (silica), an activator of factor XII, and $\mathrm{CaCl}_{2}$. This leads to a stable clot being formed. The time from activation to the formation of a stable clot is recorded in seconds and represents the aPTT. ${ }^{33}$

Mixing Test: A mixing test was performed by making a 1:1 mixing of the patient's plasma with NPP. In the mixing study, patient plasma with extended aPTT and/or PT is mixed with NPP. After blending the two samples, aPTT and PT are measured. Mixing studies are used to differentiate between possible causes of prolonged screening test results, especially to differentiate between factor deficiency and pathological inhibitor involvement. ${ }^{34}$ The mixing study can be performed immediately or after incubation for some time. After mixing test, normalization of result indicates the presence of factor deficiency whereas if the result remains the same it indicates the presence of pathological inhibitors (Figure 1).

\section{Blood Film Examination for Malaria Parasites}

Malaria was diagnosed by using light microscopic examination of a stained venous blood smear (thick and thin blood film) with $10 \%$ Giemsa. Thick and thin blood film was prepared on a clean microscope slide. The slide was allowed to air dry and then fixed with methanol. Finally, it was stained with $10 \%$ Giemsa stain. ${ }^{35}$

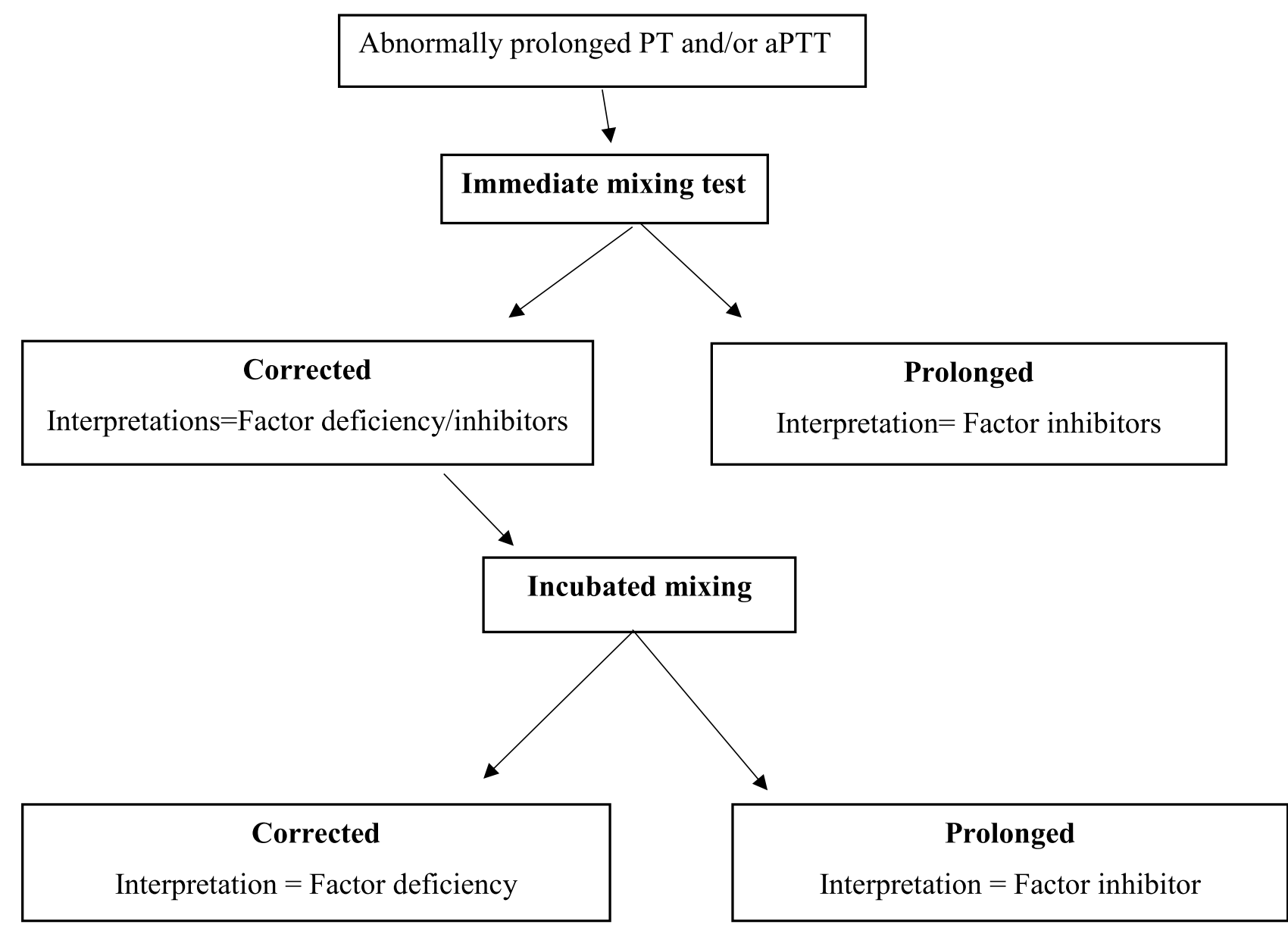

Figure I Algorithm of mixing study for the determination of factor deficiency and pathological factor inhibitors. 


\section{Data Quality Control Measures}

Sociodemographic and Clinical Data Quality Control Measures

The questionnaire was prepared in English and translated to Amharic then converted back to English to check for uniformity. The pretest of the questionnaire was done on 5\% of the participants at Maraki Health center. All study participants were informed about the purpose and significance of the study before data collection to make them fully concerned about their response. The collected data were checked daily for consistency and accuracy. Data collection was watchfully supervised by the principal investigator.

\section{Laboratory Data Quality Control Measures}

The quality of the sample was maintained by examining if it met accepted parameters such as hemolysis, clotting, volume, and collection time. After the blood is withdrawn, it was dispensed to the wall of the test tube to avoid hemolysis. Daily temperature monitoring was performed for the refrigerators that hold the sample and the reagents. All reagents were checked for expiry dates and prepared in compliance with the manufacturer's guidelines. The three-level of commercial hematology cell controls (Low, Normal, and High) were run daily. Every day before the samples were examined, an identical normal and abnormal lyophilized sample was utilized for the coagulation test. The quality of the smear and Giemsa stain were checked using known malaria positive and negative slides.

\section{Statistical Analysis}

The data were coded and double entered into Epi info version 7.2.4.0 and then transferred to SPSS version 20 for analysis. Descriptive statistics like frequencies, tables, and figures were used to summarize the characteristics of the study population. The chi-square test was used to determine the significance of the assumed association. The Shapiro-Wilks test was used to check for the normality of the data. The Hosmer and Lemeshow test statistics were performed to check for goodness-of-fitness. To determine factors associated with coagulation abnormality in DM patients, bivariable and multivariable logistic regression analysis was used. The odds ratio with its $95 \%$ interval was used to determine the strength of association between the predictor and dependent variable. Variables whose P value of less than 0.25 on Bivariable analysis was entered jointly into a multivariable logistic regression analysis. A p-value of less than 0.05 was considered statistically significant.

\section{Results}

\section{Socio-Demographic Characteristics}

A total of 357 study participants were enrolled in this study, with $52.1 \%$ (186) of them being female and $80.7 \%$ (288) residing in urban. The study participant's mean age was $54 \pm 12$ years with a range of $23-87$ years. The majority of the study participants, $72.0 \%$ (257) and 77.3\% (276) were 40-64 years old and married, respectively (Table 1).

\section{Clinical and Behavioral Characteristics}

About 43.7\% (156) of the study participants had a history of other chronic diseases. Almost all of the study participants, $99.7 \%$ (356) were taking an antidiabetic drug. Of the total study participants, $8.7 \%^{31}$ were anemic. The number of patients with hypertension was $60.5 \%$ (216) (Table 2).

\section{Prevalence of Coagulopathy}

The overall prevalence of coagulopathy was $26.6 \%$ (95/357): $17.6 \%$ (63/357) showed one of the three coagulopathy, $7.6 \%$ (27/357) showed two of the three coagulopathy, and 1.4\% (5/357) showed all three coagulopathies. From the total study participants, 12.3\% (44/357) showed shortened PT and 8.7\% (31/357) showed shortened aPTT. Thrombocytopenia was observed in 5.3\% (19/357) of the study participants. In addition to this, the prevalence of prolonged PT tests was 5.6\% (20/ 357) from whom factor deficiency and inhibitors were $95 \%{ }^{19}$ and $5 \%,{ }^{1}$ respectively. Whereas, the prevalence of the prolonged aPTT test was 3.9\% (14/357) from whom factor deficiency and inhibitors were $92.8 \%{ }^{13}$ and $7.14 \%$, respectively (Figure 2). 
Table I Socio-Demographic Characteristics of Adult T2DM Patients Attending the UoGCSH Chronic Illness Clinic, Northwest Ethiopia, 202I

\begin{tabular}{|c|c|c|c|}
\hline \multicolumn{2}{|c|}{ Sociodemographic Characteristics } & Frequency & Percentage \\
\hline Gender & Male & $|7|$ & $47.9 \%$ \\
\hline & Female & 186 & $52.1 \%$ \\
\hline Age & $18-39$ & 34 & $9.5 \%$ \\
\hline & $40-64$ & 257 & $72.0 \%$ \\
\hline & $>65$ & 66 & $18.5 \%$ \\
\hline Place of & Urban & 288 & $80.7 \%$ \\
\hline residence & Rural & 69 & $19.3 \%$ \\
\hline Educational & Unable to read and write & 97 & $27.2 \%$ \\
\hline status & Elementary & 110 & $30.8 \%$ \\
\hline & High school & 90 & $25.2 \%$ \\
\hline & College and above & 60 & $16.8 \%$ \\
\hline Occupation & Housewife & 89 & $24.9 \%$ \\
\hline & Office work & 66 & $18.5 \%$ \\
\hline & Merchant & 61 & $17.1 \%$ \\
\hline & Farmer & 53 & $14.8 \%$ \\
\hline & In retirement & 45 & $12.6 \%$ \\
\hline & Private & 43 & $12.04 \%$ \\
\hline
\end{tabular}

Table 2 Clinical and Behavioral Characteristics of Adult T2DM Patients Attending the UoGCSH Chronic Illness Clinic, Northwest Ethiopia, 202I

\begin{tabular}{|c|c|c|c|}
\hline \multicolumn{2}{|l|}{ Clinical and Behavioral Characteristics } & \multirow{2}{*}{$\begin{array}{l}\text { Frequency } \\
235\end{array}$} & \multirow{2}{*}{$\begin{array}{r}\text { Percentage } \\
65.8 \%\end{array}$} \\
\hline Duration of DM in years & $<6$ & & \\
\hline & $\geq 6$ & 122 & $34.2 \%$ \\
\hline \multirow[t]{2}{*}{ Antidiabetic drug use status } & Yes & 356 & $99.7 \%$ \\
\hline & No & I & $0.3 \%$ \\
\hline \multirow[t]{2}{*}{ Duration of antidiabetic drug use in years } & $<6$ & 236 & $66.1 \%$ \\
\hline & $\geq 6$ & 121 & $33.9 \%$ \\
\hline \multirow[t]{2}{*}{ Traditional medicine use } & Yes & 27 & $7.6 \%$ \\
\hline & No & 330 & $92.4 \%$ \\
\hline \multirow[t]{2}{*}{ Oral contraceptive use $(n=186)$} & Yes & 7 & $3.8 \%$ \\
\hline & No & 179 & $96.2 \%$ \\
\hline \multirow[t]{2}{*}{ Doing regular physical exercise } & Yes & 150 & $42.0 \%$ \\
\hline & No & 207 & $58.0 \%$ \\
\hline \multirow[t]{2}{*}{ Cigarette smoking } & Yes & 5 & $1.4 \%$ \\
\hline & No & 352 & $98.6 \%$ \\
\hline \multirow[t]{2}{*}{ History of chronic illness } & Yes & 156 & $43.7 \%$ \\
\hline & No & 201 & $56.3 \%$ \\
\hline \multirow[t]{3}{*}{ BMI } & Underweight & 12 & $3.4 \%$ \\
\hline & Normal & 198 & $55.5 \%$ \\
\hline & Overweight & 147 & $41.2 \%$ \\
\hline \multirow[t]{2}{*}{ Blood pressure } & Hypertensive & 216 & $60.5 \%$ \\
\hline & Normotensive & 141 & $39.5 \%$ \\
\hline \multirow[t]{2}{*}{ Anemia } & Anemic & 31 & $8.7 \%$ \\
\hline & Non-anemic & 326 & $91.3 \%$ \\
\hline
\end{tabular}




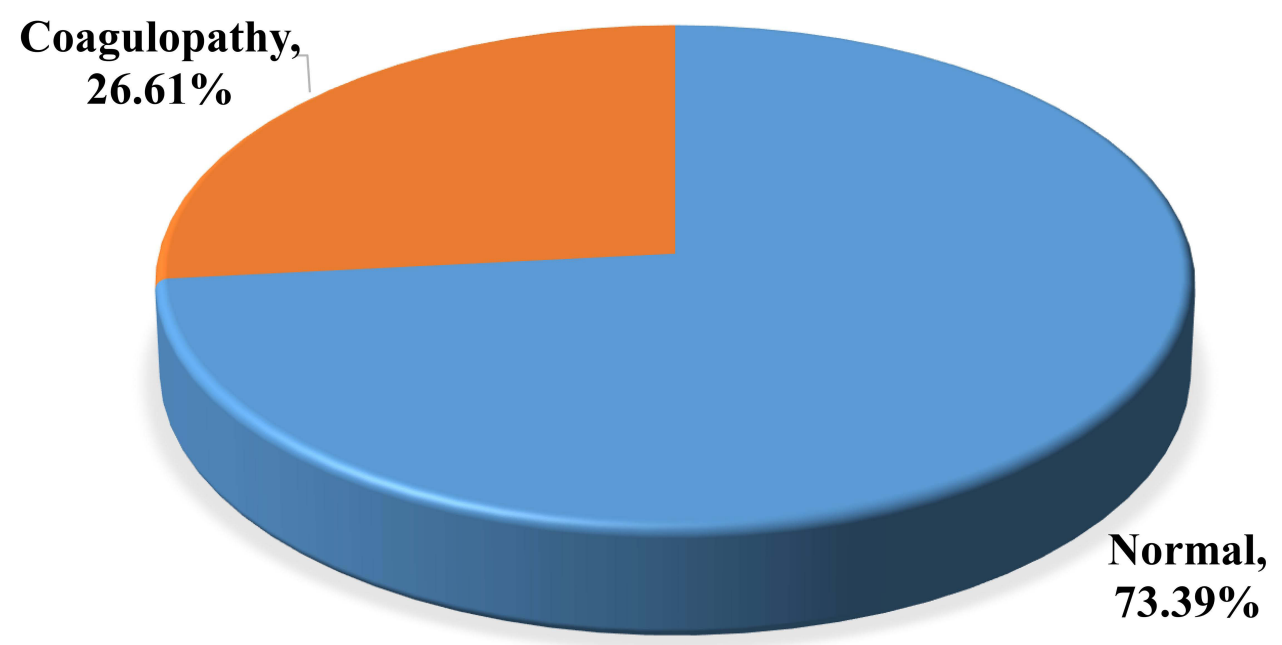

Figure 2 The types of coagulopathy identified among T2DM patients.

\section{Factors Associated with Hypercoagulation}

Since hypercoagulation is the most commonly occurring coagulopathy among DM patients, it was selected for the associated factor analysis. Therefore, in bivariable logistic regression analysis, study participants with gender ((COR) $=0.49 ; 95 \%$ CI: $0.27-$ 0.88 ), educational status (high school, $\mathrm{COR}=0.38 ; 95 \% \mathrm{CI}: 0.14-1.03$ ), physical exercise (COR $=1.42 ; 95 \%$ CI: $0.78-2.55$ ), and BMI $(C O R=0.53 ; 95 \%$ CI: $0.30-0.94)$ showed association with hypercoagulation. Consequently, these variables were subjected to multivariable logistic regression. On the other hand, the study participants' age, residence, history of chronic illness, duration of DM, duration of antidiabetic drug use, and blood pressure did not show any statistically significant association with hypercoagulation.

However, in multivariable analysis, being Female (AOR $=2.06$; 95\% CI: 1.11-3.85), education status of High school $(\mathrm{AOR}=0.26 ; 95 \% \mathrm{CI}: 0.10-0.83)$, and $\mathrm{BMI}(\mathrm{AOR}=1.94 ; 95 \% \mathrm{CI}: 1.08-3.50)$ were significantly associated with hypercoagulation. On the other hand, physical exercise did not show any statistically significant association with hypercoagulation (Table 3).

\section{Discussion}

Coagulopathy is an important public health problem among T2DM patients. It is responsible for morbidity and mortality in the world. ${ }^{36}$ Identification of T2DM patients with coagulopathy helps to reduce the risk associated with it. ${ }^{37}$ The T2DM patients are vulnerable to abnormal platelet count, PT, aPTT, and other coagulation impairments. ${ }^{38}$ Furthermore, diabetes mellitus is a pro-coagulant state. ${ }^{39}$ Hence, this study aimed to assess the prevalence and associated factors of coagulopathy among adult T2DM patients attending the UoGCSH chronic illness clinic.

In this study, the overall prevalence of coagulopathy was $26.6 \%$ (95\% CI: $22.1,31.5 \%)$. Coagulopathy in T2DM patients results from hyperglycemia conditions that result in the glycation of hemoglobin, coagulation factors, and other important proteins that are involved in the coagulation cascade. ${ }^{37}$ The prevalence of coagulopathy in this study is lower compared to a study conducted by Asrat et al in Ethiopia, which reported a $58.8 \%$ prevalence of coagulopathy in the diabetes population (Both type I \& II). ${ }^{40}$ The possible reasons for these disagreements might be associated with differences in the study population, coagulation parameters studied, the reference range used for the $\mathrm{CBC}$ and coagulation tests, the difference in sample size, and the study design used.

In the current study, the prevalence of shortened PT and aPTT were $12.3 \%$ (95\% CI: 9.10, 16.2\%) and 8.7\% (95\% CI: $6.10,11.90 \%$ ), respectively. Shortening of PT and aPTT among T2DM patients is associated with increased platelet surface proteins, plasma coagulation factors, and reduction of natural anticoagulant molecules. ${ }^{7,81-43}$ The prevalence of shortened PT and aPTT in this study is lower compared to a study conducted by Ebrahim et al in Ethiopia that reported a $16.7 \%$ and $63.3 \%$ prevalence of shortened PT and aPTT, respectively. ${ }^{44}$ The possible reason for this difference might be 
Table 3 Factors Associated with Hypercoagulation Among Adult T2DM Patients

\begin{tabular}{|c|c|c|c|c|c|c|c|}
\hline \multirow[t]{2}{*}{ Characteristics } & \multirow[t]{2}{*}{ Category } & \multicolumn{2}{|c|}{ Hypercoagulation } & \multirow[t]{2}{*}{ COR(95\% Cl) } & \multirow[t]{2}{*}{ P-value } & \multirow[t]{2}{*}{ AOR(95\% Cl) } & \multirow[t]{2}{*}{ P-value } \\
\hline & & Yes n(\%) & No $n(\%)$ & & & & \\
\hline \multirow[t]{2}{*}{ Gender } & Male & 19 (II.I\%) & 152 (88.9\%) & I & 0.018 & & 0.023 \\
\hline & Female & 38 (20.4\%) & I 48 (79.6\%) & $0.49(0.27-0.88)$ & & $2.06(1.11-3.85)$ & \\
\hline \multirow[t]{3}{*}{ Age } & $18-39$ & 7 (20.6\%) & 27 (79.4\%) & 1 & & & \\
\hline & $40-64$ & 39 (I5.2\%) & $218(84.8 \%)$ & $1.30(0.45-3.72)$ & 0.629 & & \\
\hline & $>65$ & II (16.7\%) & 55 (83.3\%) & $0.89(0.43-1.86)$ & 0.765 & & \\
\hline \multirow[t]{2}{*}{ Residency } & Urban & 46 (16.0\%) & $242(84.0 \%)$ & $1.00(0.49-2.05)$ & 0.995 & & \\
\hline & Rural & II (I5.9\%) & $58(84.1 \%)$ & I & & & \\
\hline \multirow[t]{4}{*}{ Educational status } & $\begin{array}{l}\text { Unable to read } \\
\text { and write }\end{array}$ & $18(18.6 \%)$ & 79 (8I.4\%) & I.02 (0.44-2.33) & 0.972 & $0.75(0.31-1.84)$ & 0.530 \\
\hline & Elementary & 21 (19.1\%) & 89 (80.9\%) & $1.05(0.47-2.36)$ & 0.904 & $0.85(0.37-1.96)$ & 0.698 \\
\hline & High school & 7 (7.8\%) & $83(92.2 \%)$ & $0.38(0.14-1.03)$ & 0.058 & $0.29(0.10-0.83)$ & 0.021 \\
\hline & $\begin{array}{l}\text { College and } \\
\text { above }\end{array}$ & II (18.3) & 49 (8I.7\%) & I & & & \\
\hline \multirow[t]{2}{*}{ Physical exercise } & Yes & 20 (I3.3\%) & 130 (86.7\%) & I & 0.249 & & 0.430 \\
\hline & No & 37 (17.9\%) & $170(82.1 \%)$ & $1.42(0.78-2.55)$ & & $0.77(0.4 I-1.46)$ & \\
\hline History of other & Yes & $25(16.0 \%)$ & $|3|$ (84.0\%) & $0.99(0.56-1.76)$ & 0.979 & & \\
\hline chronic illness & No & 32 (15.9\%) & $169(84.1 \%)$ & 1 & & & \\
\hline \multirow[t]{2}{*}{ Duration of DM } & $<6$ & $4 \mathrm{I}(\mathrm{I7.4 \% )}$ & 194 (82.6\%) & I & 0.291 & & \\
\hline & $\geq 6$ & $16(13.1 \%)$ & 106 (86.9\%) & $\mathrm{I} .40(0.75-2.6 \mathrm{I})$ & & & \\
\hline \multirow[t]{2}{*}{ Duration of drug use } & $<6$ & $4 \mathrm{l}(17.4 \%)$ & 195 (82.6\%) & 1 & 0.312 & & \\
\hline & $\geq 6$ & $16(13.2 \%)$ & 105 (86.8\%) & $1.38(0.74-2.58)$ & & & \\
\hline \multirow[t]{2}{*}{ Blood pressure } & Hypertensive & 37 (17.1\%) & 179 (82.9\%) & $0.80(0.44-1.44)$ & 0.458 & & \\
\hline & Normotensive & 20 (I4.2\%) & $|2|(85.8 \%)$ & 1 & & & \\
\hline \multirow[t]{2}{*}{ BMI } & Abnormal & 33 (20.8\%) & 126 (79.2\%) & $0.53(0.30-0.94)$ & 0.028 & $1.94(1.08-3.50)$ & 0.027 \\
\hline & Normal & 24 (12.1\%) & 174 (87.9\%) & I & & & \\
\hline
\end{tabular}

due to variation in study design, sample size, and the reference range used for the CBC and coagulation tests. A comparative cross-sectional study conducted in a different part of the world also revealed that there is a shortening of PT and aPTT values among T2DM patients. This study finding is supported by different studies conducted by Ankalayya et al in India, ${ }^{45}$ Mariappan et al in India, ${ }^{46}$ Karim et al in Bangladesh,${ }^{47}$ Ephraim et al in Ghana, ${ }^{37}$ Pan et al in China, ${ }^{48}$ Sapkota et al in Nepal, ${ }^{49}$ Asrat et al in Ethiopia, ${ }^{40}$ and Ambelu et al in Ethiopia, ${ }^{24}$ which showed that T2DM patients were presented with significant shortening of PT and aPTT.

In the present study, the prevalence of prolonged PT and aPTT results among T2DM patients were $5.6 \%$ (95\% CI: 3.60, $8.40 \%$ ) and $3.9 \%$ (95\% CI: 2.30, 6.30\%), respectively. The prevalence of prolonged PT is lower compared to Ebrahim et al study in Ethiopia that reported a $16.7 \%$ prevalence of prolonged PT among T2DM patients. ${ }^{44}$ Nevertheless, the prevalence of prolonged aPTT is higher compared to Ebrahim's study that reported a 1.7\% prevalence. The possible reason might be due to differences in sample size, reference range used, and the study design. A comparative cross-sectional study conducted by Alao et al in Nigeria, ${ }^{50}$ Mohammed et al in Sudan, ${ }^{51}$ Thukral et al in India, ${ }^{52}$ and Ifeanyi et al in India ${ }^{53}$ supported the presence of prolonged PT and aPTT results among T2DM patients.

Furthermore, the prevalence of thrombocytopenia among T2DM patients was 5.3\% (95\% CI: 3.30, 8.00\%). Immune responses are thought to be responsible for the pathogenesis of thrombocytopenia in diabetic patients. An elevated level of platelet-associated Immunoglobulin G is observed among T2DM patients. ${ }^{54}$ In this study, the prevalence of thrombocytopenia is in line with Ebrahim et al study in Ethiopia that reported a 5\% prevalence. ${ }^{44}$ In addition to this, studies that are conducted in different parts of the world supported the presence of thrombocytopenia among T2DM patients. A comparative cross-sectional study conducted by Pan et al in China, ${ }^{48}$ Madan et al in India, ${ }^{55}$ and Asrat et al in Ethiopia $^{40}$ showed that T2DM patients were presented with thrombocytopenia. 
In addition to this, from the prolonged PT tests, coagulation factor deficiency and pathological factor inhibitors were observed among 95\% and 5\%, respectively. Whereas, out of the prolonged aPTT tests, coagulation factor deficiency and pathological factor inhibitors were observed among $92.8 \%$ and $7.14 \%$, respectively. Pathological factor inhibitors are specific or non-specific inhibitors that halt normal coagulation cascade and result in delaying clot formation. Coagulation factor deficiency also results in a delay in the coagulation cascade. ${ }^{9,10}$ Coagulation factor deficiency may be associated with the hypercoagulation condition in T2DM patients. The hypercoagulation may result in the consumption of one or more of the coagulation factors and it will cause factor deficiency.

In the current study, being female was significantly associated with hypercoagulation. Females were two times more likely to develop hypercoagulation than male patients. Hypercoagulation in female T2DM patients is associated with an increase in fibrinogen levels, FVII: C, Von Willebrand, and plasminogen activator inhibitor-1 than males. ${ }^{56,57}$ This is in line with Chan et al in Taiwan ${ }^{13}$ and Mwambungu et al in Zambia ${ }^{14}$ studies that reported that female T2DM patients are at high risk of developing hypercoagulation. In addition, patients with abnormal BMI are also two times more likely to develop hypercoagulation than patients with normal BMI. Abnormal BMI, particularly in obesity, the risk of developing coagulation is high because adipocytokines increased activity of the coagulation factors, decreased activity of the fibrinolytic system, and endothelial dysfunction. ${ }^{58,59}$ The educational status of High school also showed a significant association with hypercoagulation among T2DM patients. Study participants with educational status of high school are less likely to develop hypercoagulation. Study participants with educational status of high school were $71 \%$ less likely to develop hypercoagulation.

\section{Conclusion}

The present study verified that the prevalence of coagulopathy among T2DM patients at the UoGCSH was a high public health problem. T2DM patients may experience numerous types of coagulopathies including hypercoagulation, a tendency to bleed, and abnormal platelet count. Moreover, factor inhibitors and factor deficiency were the cause for the coagulopathies observed among T2DM patients. Female T2DM patients and patients with abnormal BMI were two times more likely to develop hypercoagulation at the University of Gondar Comprehensive Specialized Hospital.

During a regular check-up of T2DM patients, coagulation parameters should be monitored at some time interval to diagnose coagulopathies. The hypercoagulation that is observed among T2DM patients is associated with abnormal BMI. Therefore, performing regular exercise is recommended to reduce the risk associated with it especially for female patients. In addition, for the coagulation factor deficiencies observed, a study that could assess specific coagulation factors can also be performed.

\section{Strengths and Limitations}

The study's strength includes determination of the presence of factor deficiency and inhibitory through mixing test. Factors associated with coagulopathy were assessed in detail. The first major limitation of this study was being crosssectional nature that does not reveal causal relations between independent variables and coagulopathy. Moreover, specific coagulation factor assays were not performed for the factor deficiencies determined.

\section{Abbreviations}

AOR, adjusted odds ratio; aPTT, activated partial thromboplastin time; BMI, body mass index; CBC, complete blood count; COR, crude odds ratio; DM, diabetes mellitus; EDTA, ethylene diamine tetra acetic acid; GP, glycoprotein; IDF, International Diabetic Federation; NPP, normal pooled plasma; PPP, platelet poor plasma; PT, prothrombin time; T2DM, type II diabetes mellitus; UoGCSH, University of Gondar Comprehensive Specialized Hospital.

\section{Data Sharing Statement}

All data supporting these findings is contained within the manuscript. 


\section{Ethical Considerations}

This study was conducted based on the Declaration of Helsinki. The study was conducted after ethical clearance was issued by the Ethical Review Committee of the School of Biomedical and Laboratory Sciences, College of Medicine and Health Science, the University of Gondar (Ref. No. SBLS/2746/2021). A permission letter was obtained from the UoGCSH. Informed written consents were obtained from each patient and the findings were kept confidentially. The confidentiality of the data was protected by only using codes for specimens and results and no personal identification was used. In case of abnormal results, it was informed to their medical doctors to get adequate treatment.

\section{Acknowledgments}

First of all, we would like to thank the Department of Hematology and Immunohematology, the School of Biomedical and Laboratory Sciences, the University of Gondar. Next, we acknowledge the University of Gondar Comprehensive Specialized Hospital administrative office for their willingness during the data collection. Finally, we would like to extend our gratitude to the study participants for their voluntary and cooperative participation.

\section{Author Contributions}

All authors participated in this study by conception of the study, data collection, feeding, performing the statistical analysis, drafting the manuscript, and read and edit the manuscript. All authors read and gave final approval of the version to be published; have agreed on the journal to which the article has been submitted; and agree to be accountable for all aspects of the work.

\section{Funding}

The authors received no specific funding for this work.

\section{Disclosure}

The authors report no conflicts of interest for this work and declare that there is no conflict of interest regarding the publication of this manuscript.

\section{References}

1. American Diabetes Association. Diagnosis and classification of diabetes mellitus. Diabetes Care. 2014;37:S81-S90. doi:10.2337/dc14-S081

2. Thomas C, Philipson LH. Update on diabetes classification. Med Clin. 2015;99(1):1-16. doi:10.1016/j.mcna.2014.08.015

3. American Diabetes Association. Standards of medical care in diabetes. Diabetes Care. 2014;37(Supplement 1):S14-S80. doi:10.2337/dc14-S014

4. Alam U, Asghar O, Azmi S, Malik RA. General aspects of diabetes mellitus. Handb Clin Neurol. 2014;126:211-222.

5. Roglic G, Varghese C, Cowan M. Global Report on Diabetes (World Health Organization). WHO Library Cataloguing-In-Publication Data. WHO; 2016.

6. Ceriello A. Coagulation activation in diabetes mellitus: the role of hyperglycaemia and therapeutic prospects. Diabetologia. 1993;36 (11):1119-1125. doi:10.1007/BF00401055

7. Kottke-Marchant K, Corcoran G. The laboratory diagnosis of platelet disorders. Archiv Pathol Lab Med. 2002;126(2):133-146. doi:10.5858/2002126-0133-TLDOPD

8. Morel O, Jesel L, Abbas M, Morel N. Prothrombotic changes in diabetes mellitus. Semin Thromb Hemost. 2013;39(5):477-488. doi:10.1055/ s-0033-1343888

9. Kershaw G, Orellana D. Mixing tests: diagnostic aides in the investigation of prolonged prothrombin times and activated partial thromboplastin times. Semin Thromb Hemost. 2013;39(3):283-290. doi:10.1055/s-0033-1336832

10. Kershaw G, Jayakodi D, Dunkley S. Laboratory identification of factor inhibitors: the perspective of a large tertiary hemophilia center. Semin Thromb Hemost. 2009;35(8):760-768. doi:10.1055/s-0029-1245108

11. Kershaw G, Favaloro EJ. Laboratory identification of factor inhibitors: an update. Pathology. 2012;44(4):293-302. doi:10.1097/ PAT.0b013e328353254d

12. Carr ME. Diabetes mellitus: a hypercoagulable state. J Diabetes Complications. 2001;15(1):44-54. doi:10.1016/S1056-8727(00)00132-X

13. Chan P, Pan WH. Coagulation activation in type 2 diabetes mellitus: the higher coronary risk of female diabetic patients. Diabet Med. 1995;12 (6):504-507. doi:10.1111/j.1464-5491.1995.tb00532.x

14. Mwambungu A, Kaile T, Korolova L, Kwenda J, Marimo C. Risk factors associated with hypercoagulability in type 2 diabetes mellitus patients at Ndola Central Hospital Zambia. Med J Zambia. 2014;41(2):70-80.

15. Sosothikul D, Seksarn P, Lusher JM. Pediatric reference values for molecular markers in hemostasis. J Pediatr Hematol Oncol. $2007 ; 29(1): 19-22$. doi:10.1097/MPH.0b013e3180308749

16. Shetty S, Ghosh K, Mohanty D. Comparison of four commercially available activated partial thromboplastin time reagents using a semi-automated coagulometer. Blood Coagulat Fibrinoly. 2003;14(5):493-497. doi:10.1097/00001721-200307000-00011 
17. Benzon HT, Park M, McCarthy RJ, Kendall MC, Lindholm PF. Mixing studies in patients with prolonged activated partial thromboplastin time or prothrombin time. Anesthes Analges. 2019;128(6):1089-1096. doi:10.1213/ANE.0000000000003457

18. Horlocker TT, Vandermeulen E, Kopp SL, Gogarten W, Leffert LR, Benzon HT. Regional anesthesia in the patient receiving antithrombotic or thrombolytic therapy: American Society Of Regional Anesthesia And Pain Medicine evidence-based guidelines. Region Anesthes Pain Med. 2018;43(3):263-309. doi:10.1097/AAP.0000000000000763

19. Smit C, Hallett TB, Lange J, Garnett G, de Wolf F. Late entry to HIV care limits the impact of anti-retroviral therapy in The Netherlands. PLoS One. 2008;3(4):e1949. doi:10.1371/journal.pone.0001949

20. International Diabetes Federation. IDF diabetes atlas, 9th edn. Brussels, Belgium; 2019:36-64. Available from: https://www.diabetesatlas.org. Accessed February 15, 2022.

21. Colagiuri S, Guariguata L, Motala A, Ogurtsova K. Global and regional diabetes prevalence estimates for 2019 and projections for 2030 and 2045 : results from the International Diabetes Federation Diabetes Atlas, 9 (th) edition. Diabetes Res Clin Pract. 2019;157:107843. doi:10.1016/j. diabres.2019.107843

22. International Diabetes Federation. IDF Africa members, Ethiopia; 2020. Available from: https://idf.org/our-network/regions-members/africa/ members/9-ethiopia.html. Accessed February 15, 2022.

23. Asrat D, Tesfaye G, Gedefaw L, Addisu W, Yemane T. Hemostatic abnormality and associated factors in diabetic patients at Jimma University Specialized Hospital, Jimma, Southwest Ethiopia: a comparative cross-sectional study. Ethiop J Health Sci. 2019;29(2):253-256.

24. Ambelu YA, Shiferaw MB, Abebe M, Enawgaw B. Prothrombin time, activated partial thromboplastin time and platelet counts of type II diabetes mellitus: a comparative study. J Diabetes Metabol Disord. 2018;17(2):117-121. doi:10.1007/s40200-018-0347-5

25. Population Census Commission. Summary and statistical report of the 2007 population and housing census. Population size by age and sex. 2008:314.

26. Deressa T, Damtie D, Workineh M, Genetu M, Melku MJE. Anemia and thrombocytopenia in the cohort of HIV-infected adults in northwest Ethiopia: a facility-based cross-sectional study. EJIFCC. 2018;29(1):36.

27. Aynalem M, Shiferaw E, Gelaw Y, Enawgaw B. Coagulopathy and its associated factors among patients with a bleeding diathesis at the University of Gondar Specialized Referral Hospital, Northwest Ethiopia. Thromb J. 2021;19(1):36. doi:10.1186/s12959-021-00287-6

28. Keohane EM, Otto CN, Walenga JM. Rodak's Hematology-E-Book: Clinical Principles and Applications. Elsevier Health Sciences; 2019.

29. Patel SM, Gupta S, Patel MM, Mahadik JD, Patel KA, Patel AS. A study of coagulation profile in neoplastic conditions. Int J Med Sci Public Health. 2016;5(3):402-408. doi:10.5455/ijmsph.2016.1807201565

30. World Health Organization. The Global Prevalence of Anemia in 2011. Geneva: WHO; 2015.

31. Sultan A. Five-minute preparation of platelet-poor plasma for routine coagulation testing. East Mediterr Health J. 2010;16(2):233-236. doi:10.26719/2010.16.2.233

32. Ignjatovic V. Prothrombin time/international normalized ratio. Methods Mol Biol. 2013;992:121-129.

33. Ignjatovic V. Activated partial thromboplastin time. Methods Mol Biol. 2013;992:111-120.

34. Miller CH. Chapter 130 - mixing studies. In: Shaz BH, Hillyer CD, Reyes Gil M, editors. Transfusion Medicine and Hemostasis. Third ed. Elsevier; 2019:783-784.

35. Chotivanich K, Silamut K, Day N. Laboratory diagnosis of malaria infection. Austr J Med Sci. 2006;27(1):11.

36. Owaidah T, Saleh M, Alzahrani H, et al. Prevalence of bleeding symptoms among adolescents and young adults in the capital city of Saudi Arabia. Adv Hematol. 2018;2018:1858241. doi:10.1155/2018/1858241

37. Ephraim RK, Awuku YA, Adu P, et al. High risk of coagulopathy among type-2 diabetes mellitus clients at a municipal hospital in Ghana. Ghana Med J. 2017;51(3):101-107. doi:10.4314/gmj.v51i3.2

38. Ilyas S, Waheed U, Saboor M. Coagulation abnormalities in diabetes mellitus. J Public Health Biol Sci. 2013;2(4):308-312.

39. Yürekli BP, Ozcebe OI, Kirazli S, Gürlek A. Global assessment of the coagulation status in type 2 diabetes mellitus using rotation thromboelastography. Blood Coagul Fibrinolysis. 2006;17(7):545-549. doi:10.1097/01.mbc.0000245292.34150.df

40. Asrat D, Tesfaye G, Gedefaw L, Addisu W, Yemane T. Hemostatic abnormality and associated factors in diabetic patients at Jimma University Specialized Hospital, Jimma, Southwest Ethiopia: a Comparative Cross-sectional Study. Ethiop J Health Sci. 2019;29(2):251-258. doi:10.4314/ ejhs.v29i2.12

41. Al-Rubeaan K, Nawaz SS, Youssef AM, Al Ghonaim M, Siddiqui K. IL-18, VCAM-1 and P-selectin as early biomarkers in normoalbuminuric type 2 diabetes patients. Biomark Med. 2019;13(6):467-478. doi:10.2217/bmm-2018-0359

42. Madan R, Gupt B, Saluja S, Kansra U, Tripathi B, Guliani BJ. Coagulation profile in diabetes and its association with diabetic microvascular complications. The Journal of the Association of Physicians of India. 2010;58:481-484.

43. Grant P. Diabetes mellitus as a prothrombotic condition. J Intern Med. 2007;262(2):157-172. doi:10.1111/j.1365-2796.2007.01824.x

44. Ebrahim H, Asrie F, Getaneh Z. Basic coagulation profiles and platelet parameters among adult type 1 and type 2 diabetes patients at Dessie Referral Hospital, Northeast Ethiopia: comparative cross-sectional study. J Blood Med. 2021;12:33-42. doi:10.2147/JBM.S287136

45. Ankalayya B, Sodhi H, Modala S, Baghel M. A comparative study of coagulation time in type 2 diabetes mellitus and healthy individuals. Int J Contemp Med Res. 2016;3(11):3170-3171.

46. Mariappan A, Deepa V, Nagendran R. Evaluation of coagulation profile in patients suffering with type-2 diabetes mellitus: a hospital based prospective study. Int J Clin Biochem Res. 2020;5(1):97-100.

47. Karim F, Akter QS, Jahan S, et al. Coagulation impairment in type 2 diabetes mellitus. J Bangla Soc Physiol. 2015;10(1):26-29. doi:10.3329/jbsp. v10i1.24614

48. Pan L, Ye Y, Wo M, et al. Clinical significance of hemostatic parameters in the prediction for type 2 diabetes mellitus and diabetic nephropathy. Dis Markers. 2018;2018:2-3. doi:10.1155/2018/5214376

49. Sapkota B, Shrestha SK, Poudel S. Association of activated partial thromboplastin time and fibrinogen level in patients with type II diabetes mellitus. BMC Res Notes. 2013;6(1):485. doi:10.1186/1756-0500-6-485

50. Alao O, Damulak D, Joseph D, Puepet F. Haemostatic profile of patients with type 2 diabetes mellitus in Northern Nigeria. Internet J Endocrinol. 2009;6(1):1-4.

51. Mohammed O. Alteration in prothrombin time, INR, partial thromboplastin time and platelets in type 2 diabetes mellitus, cross-sectional study-Sudan. World J Adv Res Rev Cardiovasc Med. 2020;5(3):129-133. doi:10.30574/wjarr.2020.5.3.0065 
52. Thukral S, Hussain S, Bhat S, Kaur N, Reddy A. Prothrombin time (PT) and activated partial thromboplastin time (APTT) in type 2 diabetes mellitus, a case control study. Int J Contemp Med Res. 2018;5(8):H5-H9.

53. Ifeanyi OE, Chukwuemeka OH, Sunday AG, Uche EC. Changes in some coagulation parameters among diabetic patients in Michael Okpara university of agriculture, Umudike, Abia state, Nigeria. World J Pharma Pharma Sci. 2014;3(4):52-61.

54. Shimizu H. Thrombocytopenia in insulin-dependent diabetes mellitus. Kitakanto Med J. 1998;48(4):283-285. doi:10.2974/kmj.48.283

55. Madan R, Gupt B, Saluja S, Kansra U, Tripathi B, Guliani B. Coagulation profile in diabetes and its association with diabetic microvascular complications. Assoc Physicians India. 2010;58:481-484.

56. Soliman GZ. Abnormalities in plasma concentration of lipids and fibrinogen of Egyptian microalbuminuric NIDDM type 2 diabetic patients. Egypt $J$ Hosp Med. 2005;21(1):66-81. doi:10.21608/ejhm.2005.18050

57. Mansfield MW, Heywood DM, Grant PJ. Sex differences in coagulation and fibrinolysis in white subjects with non-insulin-dependent diabetes mellitus. Arterioscleros Thrombos Vasc Biol. 2002;16(1):160-164. doi:10.1161/01.ATV.16.1.160

58. Reaven GM, Scott EM, Grant PJ, et al. Hemostatic abnormalities associated with obesity and the metabolic syndrome. J Thrombos Haemost. 2005;3(5):1074-1085. doi:10.1111/j.1538-7836.2005.01277.x

59. Samad F, Ruf W. Inflammation, obesity, and thrombosis. Blood. 2013;122(20):3415-3422. doi:10.1182/blood-2013-05-427708

Diabetes, Metabolic Syndrome and Obesity: Targets and Therapy

Dovepress

\section{Publish your work in this journal}

Diabetes, Metabolic Syndrome and Obesity: Targets and Therapy is an international, peer-reviewed open-access journal committed to the rapid publication of the latest laboratory and clinical findings in the fields of diabetes, metabolic syndrome and obesity research. Original research, review, case reports, hypothesis formation, expert opinion and commentaries are all considered for publication. The manuscript management system is completely online and includes a very quick and fair peer-review system, which is all easy to use. Visit http://www.dovepress. com/testimonials.php to read real quotes from published authors.

Submit your manuscript here: https://www.dovepress.com/diabetes-metabolic-syndrome-and-obesity-targets-and-therapy-journal 